\title{
Effects of neonatal exposure to the flame retardant tetrabromobisphenol-A, aluminum diethylphosphinate or zinc stannate on long-term potentiation and synaptic protein levels in mice
}

\author{
Hester S. Hendriks • Lucas A. E. Koolen - Milou M. L. Dingemans • \\ Henrik Viberg • Iwa Lee · Pim E. G. Leonards · Geert M. J. Ramakers · \\ Remco H. S. Westerink
}

Received: 7 May 2014 / Accepted: 4 September 2014 / Published online: 25 September 2014

(C) Springer-Verlag Berlin Heidelberg 2014

\begin{abstract}
Brominated flame retardants such as tetrabromobisphenol-A (TBBPA) may exert (developmental) neurotoxic effects. However, data on (neuro)toxicity of halogen-free flame retardants (HFFRs) are scarce. Recent in vitro studies indicated a high neurotoxic potential for some HFFRs, e.g., zinc stannate (ZS), whereas the neurotoxic potential of other HFFRs, such as aluminum diethylphosphinate (Alpi), appears low. However, the in vivo (neuro)toxicity of these compounds is largely unknown. We therefore investigated effects of neonatal exposure to TBBPA, Alpi or ZS on synaptic plasticity in mouse hippocampus. Male $\mathrm{C} 57 \mathrm{bl} / 6$ mice received a single oral dose of $211 \mu \mathrm{mol} / \mathrm{kg}$ bw TBBPA, Alpi or ZS on
\end{abstract}

Hester S. Hendriks and Lucas A. E. Koolen have contributed equally to this study.

H. S. Hendriks · M. M. L. Dingemans · R. H. S. Westerink $(\square)$ Neurotoxicology Research Group, Toxicology Division, Faculty of Veterinary Medicine, Institute for Risk Assessment Sciences (IRAS), Utrecht University, P.O. Box 80.177, 3508 TD Utrecht, The Netherlands

e-mail: r.westerink@uu.nl

L. A. E. Koolen

Master's Programme in Neuroscience and Cognition, Utrecht

University, 3508 TC Utrecht, The Netherlands

H. Viberg · I. Lee

Department of Environmental Toxicology, Uppsala University,

Uppsala, Sweden

P. E. G. Leonards

Institute for Environmental Studies (IVM), VU University,

Amsterdam, The Netherlands

G. M. J. Ramakers

Department of Translational Neuroscience, Brain Center Rudolf

Magnus, University Medical Center Utrecht, Utrecht,

The Netherlands postnatal day (PND) 10. On PND 17-19, effects on hippocampal synaptic plasticity were investigated using ex vivo extracellular field recordings. Additionally, we measured levels of postsynaptic proteins involved in long-term potentiation (LTP) as well as flame retardant concentrations in brain, muscle and liver tissues. All three flame retardants induced minor, but insignificant, effects on LTP. Additionally, TBBPA induced a minor decrease in post-tetanic potentiation. Despite these minor effects, expression of selected synaptic proteins involved in LTP was not affected. The flame retardants could not be measured in significant amounts in the brains, suggesting low bioavailability and/or rapid elimination/metabolism. We therefore conclude that a single neonatal exposure on PND 10 to TBBPA, Alpi or ZS does affect neurodevelopment and synaptic plasticity only to a small extent in mice. Additional data, in particular on persistence, bioaccumulation and (in vivo) toxicity, following prolonged (developmental) exposure are required for further (human) risk assessment.

Keywords Flame retardants - Developmental neurotoxicity $\cdot$ Hippocampal synaptic plasticity $\cdot$ Tetrabromobisphenol-A (TBBPA) · Aluminum diethylphosphinate (Alpi) $\cdot$ Zinc stannate $(Z S)$

$\begin{array}{ll}\text { Abbreviations } \\ \text { ACSF } & \text { Artificial cerebrospinal fluid } \\ \text { Alpi } & \text { Aluminum diethylphosphinate } \\ \text { BFR } & \text { Brominated flame retardant } \\ \text { CaMK-II } & \begin{array}{l}\text { Calcium-/calmodulin-dependent protein } \\ \text { kinase-II }\end{array} \\ \text { fEPSPs } & \text { Field excitatory postsynaptic potentials } \\ \text { GAP-43 } & \text { Growth-associated protein-43 } \\ \text { HFFR } & \text { Halogen-free flame retardant } \\ \text { IO } & \text { Input-output }\end{array}$

Abbreviations

ACSF Artificial cerebrospinal fluid

Alpi Aluminum diethylphosphinate

BFR Brominated flame retardant

CaMK-II Calcium-/calmodulin-dependent protein kinase-II

fEPSPs Field excitatory postsynaptic potentials

GAP-43 Growth-associated protein-43

IO Input-output 


$\begin{array}{ll}\text { ISI } & \text { Inter-stimulus interval } \\ \text { LTP } & \text { Long-term potentiation } \\ \text { nACh } & \text { Nicotinic acetylcholine } \\ \text { NMDA } & N \text {-methyl-D-aspartate } \\ \text { PND } & \text { Postnatal day } \\ \text { PPF } & \text { Paired-pulse facilitation } \\ \text { PPR } & \text { Paired-pulse ratio } \\ \text { PSD 95 } & \text { Postsynaptic density 95 } \\ \text { PTP } & \text { Post-tetanic potentiation } \\ \text { TBBPA } & \text { Tetrabromobisphenol-A } \\ \text { ZS } & \text { Zinc stannate }\end{array}$

\section{Introduction}

Flame retardants are widely used to prevent or slow the onset and spread of fire, thereby reducing death, injuries and property damage. Tetrabromobisphenol-A (TBBPA) is a commonly used brominated flame retardant (BFR). As a consequence of its abundant use and environmental persistence, it can nowadays be found in house dust (Abb et al. 2011) as well as in wildlife and human serum and adipose tissue samples (Covaci et al. 2009; de Wit et al. 2010; Johnson-Restrepo et al. 2008). Earlier studies have shown that BFRs, such as polybrominated diphenyl ethers (PBDEs), are clearly associated with (developmental) neurotoxicity (Dingemans et al. 2011). However, the potentially adverse effects of TBBPA on the (developing) nervous system are less extensively studied. Recently, it was shown that TBBPA exposure decreases the expression of $\alpha_{4} \beta_{2}$ nicotinic acetylcholine (nACh) receptors in the frontal cortex of neonatally exposed mice (Viberg and Eriksson 2011), whereas TBBPA also exerts acute modulatory effects on human $\mathrm{GABA}_{\mathrm{A}}$ and $\mathrm{nACh}$ receptors in vitro (Hendriks et al. 2012a). GABA $A_{A}$ and nACh receptors are widely distributed throughout the central nervous system and are critically involved in a variety of processes, including development and differentiation of the nervous system, learning, memory and synaptic plasticity (D'Hulst et al. 2009; Dwyer et al. 2009). Fetal and neonatal exposure to BFRs such as TBBPA may thus have adverse effects on neurodevelopment, especially during the brain growth spurt (as has been previously shown for, e.g., PBDEs; Eriksson et al. 2001, 2002; Viberg et al. 2003a, b, 2004), which in humans starts during the third trimester of pregnancy, peaks just before birth and continues throughout the first 2 years of life (Dobbing and Sands 1979).

Considering the concerns associated with exposure to TBBPA and PBDEs (Dingemans et al. 2011), there is a clear need to replace some BFRs by safer and less persistent alternative flame retardants, such as halogen-free flame retardants (HFFRs). However, the (neuro)toxic potential of such alternative flame retardants is largely unknown (for review, see (Waaijers et al. 2013a). The acute environmental toxicity of aluminum diethylphosphinate (Alpi; a phosphorous flame retardant) and zinc stannate (ZS; an inorganic flame retardant) investigated in water fleas (Daphnia magna) indicated that both substances could be suitable candidates for BFR replacement (Waaijers et al. 2013b). Recently, we investigated the in vitro neurotoxic potential of a number of suggested HFFRs on several neurotoxic endpoints in vitro, including cytotoxicity, production of reactive oxygen species (ROS), calcium homeostasis and nACh receptor function (Hendriks et al. 2012b, 2014), with the purpose of prioritizing HFFRs for substitution of BFRs. In these studies, Alpi was classified as having negligible neurotoxic potency in vitro and thus as a potentially suitable replacement of some BFRs. In the same studies, $\mathrm{ZS}$ was classified as having a high neurotoxic potency in vitro and thus likely unsuitable as replacement of BFRs (Hendriks et al. 2014). However, as in vitro models generally lack metabolism and some of the more sophisticated interactions that are present in the intact brain, extrapolation of experimental in vitro data to the in vivo toxicity of HFFRs is difficult. Such extrapolation is further hampered by the general absence of in vivo toxicity data of HFFRs, including data on toxicokinetics, such as the possibility to pass the blood-brain barrier.

To bridge the gap between our experimental in vitro data and the in vivo situation, we performed ex vivo validation experiments to determine the neurophysiological effects of a single neonatal exposure to TBBPA, Alpi or ZS. Long-term potentiation (LTP) is an extensively studied form of synaptic plasticity (Blundon and Zakharenko 2008) and was previously shown to be affected by neonatal exposure to BDE-47 (Dingemans et al. 2007) and BDE-209 (Xing et al. 2009). Using comparable dosing protocols as used in these studies (mice exposed on PND 10, LTP measurements on PND 17-19), the neurodevelopmental hazard and risk of the (alternative) flame retardants can be compared with existing data on PBDEs. Since induction and maintenance of LTP requires activation of specific neurotransmitter receptors and protein kinases, including calcium-/calmodulin-dependent protein kinaseII (CaMK-II; Lisman et al. 2012), levels of several critical synaptic proteins in brain tissue were also measured. Furthermore, we investigated paired-pulse facilitation (PPF), a form of short-lasting plasticity that reflects presynaptic function (Schulz et al. 1994), to reveal possible presynaptic effects. Finally, levels of TBBPA, Alpi and ZS were measured in brain, muscle and liver tissues of the exposed mice to relate possible effects to internal doses and gain insight in the bioavailability and distribution of these compounds. 


\section{Materials and methods}

\section{Chemicals}

The flame retardants were purchased from different companies at the highest purity available: TBBPA ( $>99 \%$, SigmaAldrich, Zwijndrecht, The Netherlands), Alpi (>99 \%, Clariant, Knapsack, Germany) and ZS (>98 \%, William Blythe, Acrington, England, United Kingdom). The vehicle components egg lecithin ( $\mathrm{L}-\alpha$-phosphatidylcholine) and peanut oil (oleum arachidis) and all other chemicals were obtained from Sigma-Aldrich (Zwijndrecht, The Netherlands) unless otherwise indicated.

\section{Animals}

Male C57B1/6 mice pups (litter culled to five pups each) with dam (Harlan, Venray, The Netherlands) were housed in a standard animal facility on a 12-h light/dark cycle with food and water ad libitum. All experiments were conducted in accordance with Dutch law and approved by the Ethical Committee for Animal Experimentation of Utrecht University.

Male C57B1/6 pups received a single oral dose of vehicle (control), TBBPA [115 mg $(211 \mu \mathrm{mol}) / \mathrm{kg}$ bw], Alpi [82.4 $\mathrm{mg}(211 \mu \mathrm{mol}) / \mathrm{kg} \mathrm{bw}]$ or ZS [48.9 mg $(211 \mu \mathrm{mol}) /$ $\mathrm{kg}$ bw ZS] (all $10 \mathrm{ml} / \mathrm{kg}$ bw, i.e., $10 \mu \mathrm{l} / \mathrm{g} \mathrm{bw}$ ) via a metal feeding needle on PND 10, i.e., during the peak of the brain growth spurt. This dose is tenfold higher than those used in earlier studies on TBBPA (Eriksson et al. 2001; Viberg and Eriksson 2011) that exerted only minor effects. To allow for comparison of TBBPA with both HFFRs, equimolar concentrations were used for Alpi and ZS. The vehicle consisted of a 1:10 (wt/wt) mixture of egg lecithin and peanut oil, which was sonicated with water to obtain a $20 \%$ (wt/ wt) fat/water emulsion. Experimental groups consisted of mice from at least four different litters. To exclude confounding effects induced by, e.g., time and season, exposures were randomized (different experimental conditions within a litter) and effects were measured on different weekdays.

Hippocampal slice preparation and tissue collection

On PND 17-19 (just after the peak of the brain growth spurt), exposed pups were killed by decapitation under inhalation anesthesia (isoflurane). The brain was rapidly dissected on ice, and the two hemispheres were separated. One hemisphere was used to prepare hippocampal slices as described previously (Dingemans et al. 2007; Notenboom et al. 2010). Briefly, 250- $\mu \mathrm{m}$ coronal slices were cut in icecold carbogenated $\left(95 \% \mathrm{O}_{2}\right.$ and $\left.5 \% \mathrm{CO}_{2}\right)$ artificial cerebrospinal fluid (ACSF, containing in mM: $124 \mathrm{NaCl}, 3.3$
$\mathrm{KCl}, 1.3 \mathrm{MgSO}_{4}, 1.2 \mathrm{KH}_{2} \mathrm{PO}_{4}, 2.5 \mathrm{CaCl}_{2}, 20 \mathrm{NaHCO}_{3}$, 10 glucose) using a Leica VT1200s vibratome (Leica Microsystems, Wetzlar, Germany). The slices were allowed to stabilize at room temperature in carbogenated ACSF for at least $1 \mathrm{~h}$.

Non-cortex tissue (hippocampus and midbrain) of unused hemispheres, cortex tissues, hind limb muscles and livers were collected and stored at $-80{ }^{\circ} \mathrm{C}$ until further chemical and protein analysis (per treatment, tissue samples of 10-15 mice from at least four different litters were collected).

Extracellular recording of field potentials

Hippocampal slices were individually transferred to a recording chamber and superfused with carbogenated ACFS $\left(\sim 32{ }^{\circ} \mathrm{C}, \sim 2 \mathrm{ml} / \mathrm{min}\right)$. Synaptic transmission and activity-dependent plasticity in the hippocampal CA1 region were investigated by measuring field excitatory postsynaptic potentials (fEPSPs) as described previously (Dingemans et al. 2007; Notenboom et al. 2010), with minor modifications. Synaptic responses were evoked by local extracellular stimulation of the Schaffer collateralcommissural pathway using bipolar borosilicate electrodes (see Fig. 1a). Data were recorded with an EPC10 amplifier (Heka, Lambrecht, Germany), digitized at $20 \mathrm{kHz}$ and analyzed off-line using Igor Pro 5.05 A (Wavemetrics Inc., USA).

Input-output (IO) curves were made to determine possible treatment-induced changes in basal excitability and thresholds for synaptic transmission. Stimulation intensities for threshold and maximum fEPSP were determined for every slice using four single stimuli with increasing intensity. After obtaining the IO curve, the stimulus intensity that evoked half-maximal fEPSPs was determined and used during the remainder of the experiment. To determine the degree of paired-pulse facilitation [PPF, a form of shortterm plasticity that reflects presynaptic function (Schulz et al. 1994)], paired pulses were delivered at inter-stimulus intervals (ISI) of 50, 100 and $200 \mathrm{~ms}$, and the ratio of the second and first response amplitude was calculated for each interval (paired-pulse ratio, PPR). Slices with a maximum fEPSP amplitude of $\geq 1 \mathrm{mV}$ and with stable baseline fEPSP (half-maximal fEPSP was evoked every $30 \mathrm{~s}$ ) for $30 \mathrm{~min}$ were included. LTP was induced with a single tetanic stimulation $(100 \mathrm{~Hz}, 1 \mathrm{~s})$, and post-tetanic fEPSPs were recorded for $60 \mathrm{~min}$.

For data analysis, amplitudes of the fEPSPs (measured every $30 \mathrm{~s}$ ) were determined (see Fig. 1b). Each recording was normalized to the average amplitude of the last 10 baseline fEPSPs. Potential flame retardant-induced effects on synaptic plasticity were assessed by measuring the average fEPSP amplitude per animal $(n=6-9)$ in different time 

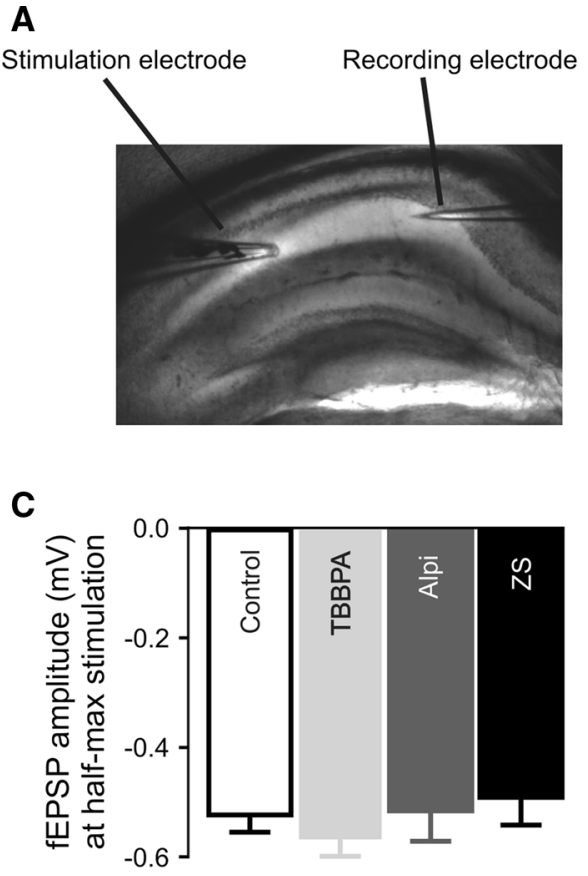

Fig. 1 Example of a coronal hippocampal slice with stimulation and recording electrodes placed along the Schaffer collateral-commissural fiber trajectory in CA1 of mouse hippocampus for measurement of fEPSPs (a). For data analysis, the amplitude was determined as shown in the representative fEPSP recording (b). Baseline fEPSP amplitude at half-maximal stimulation as a measure of synaptic transmission did not show any effect of neonatal exposure to TBBPA, Alpi

windows: 0-7.5 min after tetanic stimulation (post-tetanic potentiation; PTP) and 20-30 min after tetanic stimulation (long-term potentiation; LTP, comparable to Dingemans et al. 2007) as well as 50-60 min after tetanic stimulation (sustained LTP). Per treatment group, six to nine animals from at least four different litters were used.

Slot-blot analysis for CaMK-II, GAP-43, GluR1, PSD 95 and synaptophysin protein expression

To minimize the number of required experimental animals, we chose to analyze protein expression in cortex of the animals used for hippocampal LTP studies. Cortices were homogenized in a RIPA cell lysis buffer (containing in mM: 50 tris $\mathrm{HCl}$ (pH 7.4), $150 \mathrm{NaCl}, 1$ EDTA, 1 EGTA, 20 sodium pyrophosphate, 2 sodium orthovanadate, $1 \%$ Triton X-100 and $1 \%$ sodium deoxycholate; Assay Designs) with the addition of $0.5 \%$ Protease Inhibitor Cocktail Set III (Calbiochem). The homogenate was then centrifuged at $14,000 \times g$ for $15 \mathrm{~min}$ at $4{ }^{\circ} \mathrm{C}$, and the protein content of the supernatant was measured using the BCA method (Pierce). Subsequently, the supernatant was stored at $-80{ }^{\circ} \mathrm{C}$ until use.

\section{B}
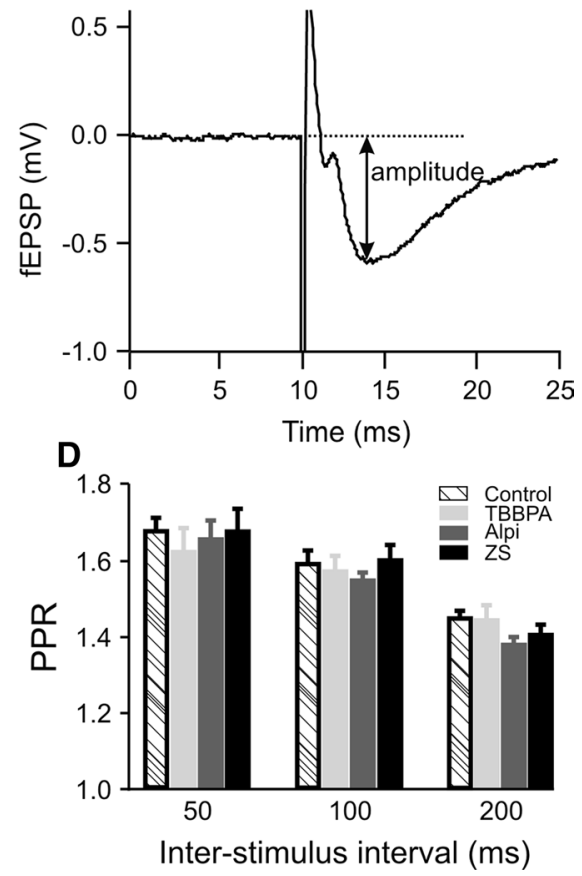

or ZS compared with control (c). Short-term plasticity, expressed as paired-pulse ratio (PPR) at different inter-stimulus intervals, following exposure to control, TBBPA, Alpi or ZS did not show any effects of neonatal exposure on PND 10, indicating that the tested flame retardants do not affect short-term plasticity in the CA1 region of the hippocampus (d). Bar graphs represent mean values \pm SEM, $n=6-9$

The slot-blot analysis was performed as described previously (Viberg et al. 2008a, b). Briefly, for CaMK-II and growth-associated protein-43 (GAP-43), $4 \mu \mathrm{g}$ of protein was optimal; for GluR1 and synaptophysin, $3 \mu \mathrm{g}$; and for postsynaptic density 95 (PSD 95), $5 \mu \mathrm{g}$ protein. The protein amount was diluted to a final volume of $200 \mu 1$ with sample buffer (in mM: $120 \mathrm{KCl}, 20 \mathrm{NaCl}, 2 \mathrm{NaHCO}_{3}, 2 \mathrm{MgCl}_{2}$, 5 HEPES (pH 7.4), $0.05 \%$ Tween-20, $0.2 \% \mathrm{NaN}_{3}$ ) and applied in duplicate to a nitrocellulose membrane $(0.45 \mu \mathrm{m}$, Bio-Rad, Sundbyberg, Sweden), using a Bio-Dot SF microfiltration apparatus (Bio-Rad). The membranes were fixed in $25 \%$ isopropanol and $10 \%$ acetic acid solution, washed and blocked for $1 \mathrm{~h}$ at room temperature in $5 \%$ nonfat dry milk containing $0.03 \%$ Tween-20. The membranes were then incubated overnight at $4{ }^{\circ} \mathrm{C}$ with either mouse monoclonal CaMK-II antibody (1:5,000; MAB8699, Chemicon), rabbit polyclonal GAP-43 antibody (1:10,000; AB5220, Chemicon), rabbit polyclonal GluR1 antibody (1:1,000; AB1504, Millipore), mouse monoclonal PSD 95 antibody (1:10,000; MABN68, Millipore) or mouse monoclonal synaptophysin antibody (1:10,000; 573822, Calbiochem). Immunoreactivity was detected using a horseradish peroxidase-conjugated secondary antibody against mouse $(1: 20,000 ; 074-1806$, 
KPL, VWR, Stockholm, Sweden) or rabbit (1:20,000; 0741506, KPL, VWR). Immunoreactive bands were detected using an enhanced chemiluminescent substrate (Pierce, Super Signal West Dura, Bio-Rad, Sundbyberg, Sweden) with imaging on a LAS-1000 (Fuji Film, Tokyo, Japan). The intensity of bands was quantified using IR-LAS 1000 Pro (Fuji Film). For each exposure condition, six animals were used originating from at least four different litters.

Internal dose analysis

For determination of the internal dose of TBBPA-exposed mice, small amounts of liver, muscle and non-cortex brain tissues (about 30-200 mg) were freeze-dried ( $n=4-5$ samples per tissue from at least four different litters). The freeze-dried samples were transferred to glass tubes, and $1 \mathrm{ml}$ of hexane/acetone $(3: 1, \mathrm{v} / \mathrm{v})$ and $100 \mu \mathrm{l}$ internal standard $\left({ }^{13} \mathrm{C}\right.$ labeled TBBPA, Cambridge Isotope Laboratories, Apeldoorn, The Netherlands) were added. The samples were agitated (Vortex) for $30 \mathrm{~s}$ followed by an ultrasonic extraction $(5 \mathrm{~min})$. The extracts were collected, and the extraction step was repeated two times with hexane/acetone, agitation and ultrasonic extraction. The recombined extracts were evaporated to $1 \mathrm{ml}$ with a gentle stream of nitrogen. These extracts were cleaned using a Pasteur pipette filled with $1 \mathrm{~g}$ of $40 \%$ sulfuric acid silica (Silica gel 60, Merck, Darmstadt, Germany). TBBPA was eluted from the extracts with $5 \mathrm{ml}$ dichloromethane (Picograde, Promochem $\mathrm{GmbH}$, Wesel, Germany) and was subsequently evaporated to $0.5 \mathrm{ml}$, followed by adding $1 \mathrm{ml}$ iso-octane and evaporation to $0.5 \mathrm{ml}$. The final extracts were measured with gas chromatography (GC6890N, Agilent, Joint Analytical Systems Benelux B.V., Eindhoven, The Netherlands) combined with mass spectrometry in the electron capture negative ionization mode (5975 MSD, Agilent). A DB-5 column $(15 \mathrm{~m} \times$ I.D $0.25 \mathrm{~mm} \times$ film $0.25 \mu \mathrm{m}, \mathrm{J} \& \mathrm{~W}$ Scientific, Agilent), splitless injection and helium as carrier gas were used. The $\mathrm{m} / \mathrm{z} 79,81$ ions and specific ions were used for the detection and quantification of TBBPA and ${ }^{13} \mathrm{C}-\mathrm{TBBPA}$.

Liver, muscle and non-cortex brain samples $(n=4-5$ samples per tissue per compound from at least three different litters) of Alpi- or ZS-exposed mice were freeze-dried and homogenized. A maximum of $100 \mathrm{mg}$ of dried material was added to microwave digestion vessels, and $5 \mathrm{ml}$ of ultrapure water (milliQ, Millipore) and $5 \mathrm{ml} 65 \%$ nitric acid (Ultrex II, Baker, VWR, Amsterdam, The Netherlands) were added. After microwave digestion (MDS 2000, MW1, Beun-de Ronde, Abcoude, The Netherlands), $10 \mathrm{ml}$ ultrapure water was added to the vessels. The digests were diluted and analyzed by high-resolution inductively coupled plasma mass spectrometry (HRICP-MS; (Giessmann and Greb 1994; Krystek and Ritsema 2009). The elements of $\mathrm{Zn}$ and $\mathrm{Al}$ were measured in the medium resolution mode. For the quantification, external calibrations with internal standard correction were applied and the internal standard (rhodium) was added online.

\section{Statistical analyses}

LTP was defined as $>15 \%$ increase above baseline, with all changes in amplitude $>15 \%$ being significant $(p<0.05 ; t$ test). Normalized data were averaged across each selected time window (PTP, LTP and sustained LTP) for each individual animal in each group. The mean of the average fEPSP (per window) of the animals per group was then used for statistical analysis. Internal dose analysis of exposed animals was background corrected using values from control animals. All data are presented as mean \pm standard error of the mean (SEM) unless otherwise noted. The four experimental groups were statistically compared by one-way ANOVA with post hoc Newman-Keuls test (GraphPad Prism 6.01). Unpaired Student's $t$ tests were used for all other data. A $p$ value of $<0.05$ indicates statistical significance.

\section{Results}

\section{General toxicity}

Pups exposed to TBBPA, Alpi or ZS did not differ in body weight compared with the pups exposed to the vehicle control (data not shown), indicating the absence of general toxicity or treatment-dependent food competition.

\section{Basal excitability and synaptic transmission}

None of the flame retardants affected the IO relationship (data not shown), the magnitude of the baseline fEPSP amplitude at half-maximal (control: $-0.52 \pm 0.03 \mathrm{mV}$; TBBPA: $-0.56 \pm 0.03 \mathrm{mV}$; Alpi: $-0.51 \pm 0.05 \mathrm{mV}$; $\mathrm{ZS}$ : $-0.48 \pm 0.05 \mathrm{mV}$; see Fig. 1c) or maximal stimulation ( $\geq 1 \mathrm{mV}$; data not shown). To assess possible flame retardant-induced presynaptic effects, paired-pulse facilitation (PPF) was examined and expressed as a paired-pulse ratio (PPR) showing an increased response to the second of two identical stimuli separated by an inter-stimulus interval (ISI) of 50-200 ms. In controls, PPR decreased from $1.67 \pm 0.04$ (ISI $50 \mathrm{~ms}$ ) to $1.45 \pm 0.02$ (ISI $200 \mathrm{~ms}$ ), and none of the treatments affected PPR compared with control animals (Fig. 1d).

\section{Long-term potentiation}

LTP was induced by tetanic stimulation $(100 \mathrm{~Hz}$, $1 \mathrm{~s})$, which resulted in an immediate increase in the fEPSP amplitude (see Fig. 2a). During PTP (i.e., the 


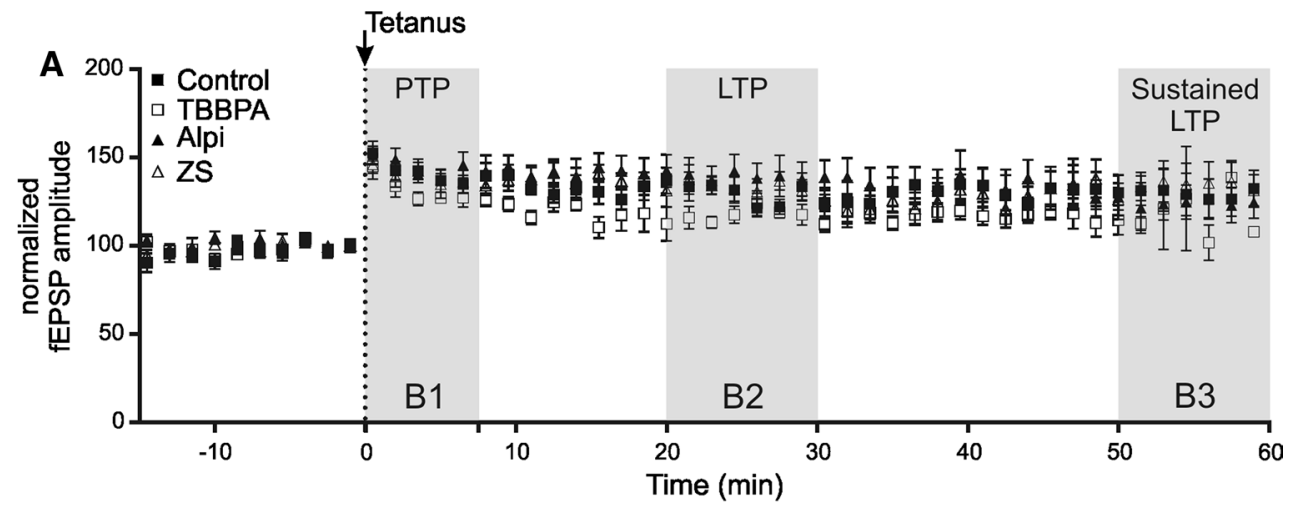

B
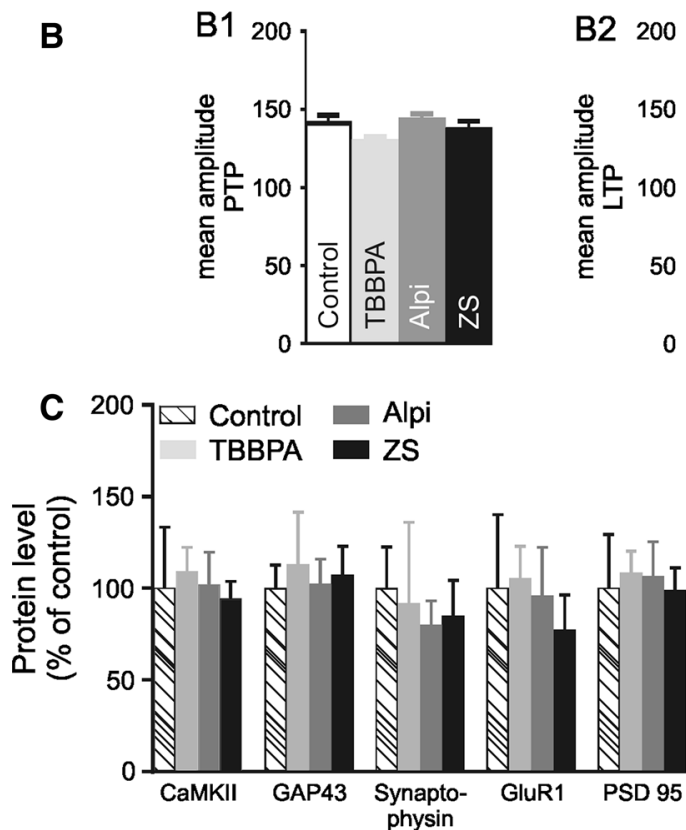

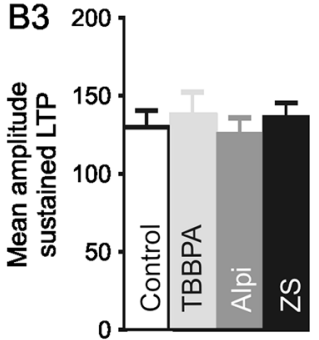

D

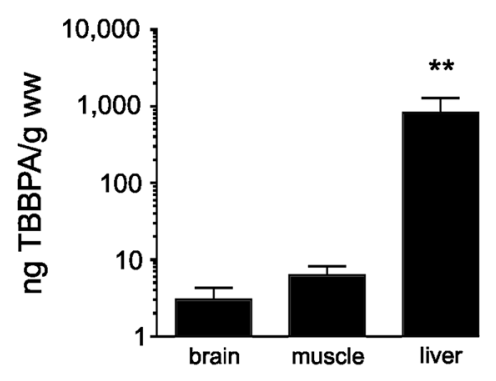

Fig. 2 Normalized fEPSP amplitude data $( \pm$ SEM) representing baseline, tetanic stimulation (arrow), PTP, LTP, and sustained LTP in hippocampal slices of control and neonatal exposed mice (a) (note: for better graphical representation only every third point in the timeline is shown). Bar graphs show mean fEPSP amplitudes \pm SEM $(n=6-9)$ of control and exposed mice in the selected windows $(\mathbf{b}$; PTP in B1, LTP in B2 and sustained LTP in B3). No differences in

first 7.5-min post-tetanus), the potentiation of the fEPSP amplitude in slices from TBBPA exposed animals was slightly but not significantly lower compared with control animals (control: $140.9 \pm 5.3 \%$; TBBPA: $128.7 \pm 3.0 \%$ ), while effects comparable to control were observed for Alpi and ZS (Alpi: $143.3 \pm 4.0 \%$; ZS: $136.7 \pm 5.7 \%)$. After PTP, the fEPSP amplitude decreased but remained well above the baseline level for at least $60 \mathrm{~min}$ in all experimental groups (see also Fig. 2a, b). During LTP (i.e., 20-30 min post-tetanus), the potentiation of the fEPSP amplitude for TBBPA was again slightly but not significantly lower compared levels of postsynaptic proteins essential for LTP induction and maintenance were observed in cortices of control and neonatally exposed animals. Bar graphs represent mean values $\pm \mathrm{SD} ; n=6$ (c). Significant levels of TBBPA were measured in livers of TBBPA exposed mice. Bars represent mean concentration (ng/g ww) \pm SEM; $n=4-5$ animals $(\mathbf{d}) . * * p<0.001$ versus control

with control animals (control: $130.7 \pm 4.9 \%$; TBBPA: $117.3 \pm 4.5 \%$ ), while the potentiation of the fEPSP amplitude was slightly but not significantly increased in the Alpi group $(138.1 \pm 8.8 \%)$. The degree of potentiation in the ZS group (132.7 $\pm 6.1 \%)$ was comparable to control. During sustained LTP (50-60 min post-tetanus), the potentiation of the fEPSP amplitude in the TBBPA group was slightly, but not significantly, increased compared with control (control: $129.7 \pm 10.6 \%$; TBBPA: $136.9 \pm 15.1 \%$;), whereas the potentiation of the fEPSP amplitude was comparable to control in both the Alpi and ZS groups (Alpi: $125.2 \pm 10.5 \%$; ZS: $135.8 \pm 9.6 \%$ ). 


\section{Cortex synaptic protein expression}

To investigate whether neonatal exposure affected the expression of specific neurotransmitter receptors and protein kinases essential for induction and maintenance of LTP, protein levels of CaMK-II, GAP-43, GluR1, PSD 95 and synaptophysin were measured in the cortex of control, TBBPA-exposed, Alpi-exposed and ZS-exposed mice. No significant effects of TBBPA, Alpi or ZS exposure on the different protein levels were observed ( $n=6$ animals/ group, Fig. 2c).

Brain, muscle and liver concentrations

In order to determine internal doses in flame retardantexposed animals, non-cortex brain, muscle and liver tissues were collected, analyzed and corrected for background (values obtained from control animals). In TBBPA-exposed mice, high concentrations TBBPA were observed in the liver $[823 \pm 460 \mathrm{ng} / \mathrm{g} \mathrm{ww} ; p<0.01$ compared to control (not detected)]. Muscle $(6 \pm 2 \mathrm{ng} / \mathrm{g}$ ww, not significant) and brain $(3 \pm 1 \mathrm{ng} / \mathrm{g}$ ww, not significant, see Fig. $2 \mathrm{~d})$ contained only low levels of TBBPA. In the tissues of both Alpi- or ZS-exposed mice, concentrations $\mathrm{Al}$ as proxy for Alpi and Zn as proxy for ZS were comparable to the control group (below the limit of detection).

\section{Discussion}

Previous studies demonstrated numerous neurotoxic effects in vitro following acute exposure to BFRs and HFFRs, including changes in cell viability, production of ROS, calcium homeostasis and nACh receptor function (Hendriks et al. 2012a, b, 2014). However, the present study demonstrates that neonatal exposure of mice on PND 10 to the flame retardants TBBPA, Alpi or ZS induces only minor, insignificant, changes in LTP compared with control animals, whereas basal excitability and paired-pulse facilitation are not affected (Figs. 1, 2). To confirm the validity of this conclusion, we performed additional measurements of protein expression. Though we cannot exclude transient changes in protein expression shortly after dosing and/ or induction of LTP, our measurements demonstrate that basal expression levels of several synaptic proteins essential for neurotransmission and (long-term) synaptic plasticity are also unaltered (Fig. 2). Similarly, in the absence of extensive studies on kinetics, we cannot exclude that tissue concentrations have been higher at earlier time points after dosing, but we could not detect significant amounts of flame retardants in (non-cortex) brain tissue of the exposed mice. We therefore conclude that the minor flame retardantinduced effects on LTP following a single oral exposure on
PND 10 may not be sufficient to affect normal brain development, function or plasticity to an adverse degree.

Using a comparable dosing paradigm, i.e., a single oral exposure on PND 10, it was previously shown that BDE47 induced clear and permanent alterations in spontaneous behavior and learning and memory functions (Eriksson et al. 2001), expression of synaptic proteins (CaMK-II and GluR1) and synaptic plasticity (PTP and LTP; Dingemans et al. 2007). Using this dosing paradigm (albeit at a tenfold lower dose $(21 \mu \mathrm{mol} / \mathrm{kg} \mathrm{bw})$ than in the present study $(211 \mu \mathrm{mol} / \mathrm{kg} \mathrm{bw}))$, it was shown that TBBPA reduced the expression of $\alpha_{4} \beta_{2}$ nACh receptors in mice frontal cortex $24 \mathrm{~h}$ after exposure (Viberg and Eriksson 2011). However, in line with the present study, TBBPA did not affect expression levels of CaMK-II, GAP-43 and synaptophysin in mice frontal cortex (Viberg and Eriksson 2011). Moreover, using this dosing protocol, it has also been shown that TBBPA $(21 \mu \mathrm{mol} / \mathrm{kg}$ bw) did not induce permanent aberrations in spontaneous behavior or learning and memory functions (Eriksson et al. 2001), indicating the absence of neurodevelopmental effects. The uncertainty whether or not TBBPA induces developmental neurotoxicity is further underlined by gestational/lactational exposure studies which indicate that developmental exposure of rats resulted in alterations of neuronal migration in the dentate gyrus (Saegusa et al. 2012), while several critical neurochemical parameters were not affected (Saegusa et al. 2009). Additionally, a one-generation reproduction study in rats showed that fear memory in adult rats is not affected, although effects on auditory neuron function were observed (Lilienthal et al. 2008), and a comparable reproduction study indicated that thyroid hormones, which are also involved in neuronal development, are affected by TBBPA (Van der Ven et al. 2008). Although several endocrine effects were observed in rats following chronic exposure (Van der Ven et al. 2008), it remains debatable whether the observed disturbances of (thyroid) hormones affect the developing brain to such a degree that (developmental) neurotoxicity occurs. Nonetheless, acute exposure ( $3 \mathrm{~h}$ before the behavioral tests) of adult mice to TBBPA ( $\geq 0.1 \mathrm{mg} / \mathrm{kg} \mathrm{bw}$ ) has been reported to induce behavioral effects [e.g., increase in horizontal movement activities and more freezing behavior (Nakajima et al. 2009)] that were accompanied by a rapid increase in brain TBBPA levels.

Upon oral exposure, TBBPA may thus reach the brain (Nakajima et al. 2009; Viberg and Eriksson 2011) to exert (transient) effects on neuronal development and function in rodents. However, TBBPA has a short half-life $[<3$ days in rats (Brady 1979); 6.6 days in humans (Geyer et al. 2004)], low systemic bioavailability (Knudsen et al. 2014), and elimination from the brain appears to be efficient (Fig. 2c; Viberg and Eriksson 2011). Consequently, the likelihood for TBBPA-induced neurodevelopmental effects appears 
limited, unless exposure is to both chronic and high doses. Nevertheless, in mice on PND 10, the blood-brain barrier is not yet fully developed, which may result in higher TBBPA levels in the developing brain compared with a mature brain.

Though TBBPA is found in human breast milk (up to several ng/g lw; Abdallah and Harrad 2011; Shi et al. 2009) and cord serum (up to $100 \mathrm{ng} / \mathrm{g} \mathrm{lw}$; Cariou et al. 2008), and the estimated daily exposure of toddlers via dust amounts to $0.2 \mathrm{ng} / \mathrm{kg}$ bw/d (Abb et al. 2011); the current levels of human TBBPA exposure are relatively low and, taking into account the rapid excretion, may be of limited concern (see also Colnot et al. 2014). In line with this notion, epidemiological studies have so far failed to consistently find an association between human TBBPA levels and adverse neurological/behavioral effects (Kicinski et al. 2012; Williams and DeSesso 2010). However, it should be noted that the absence of an association between human levels of a toxicant and human adverse effects does not imply that a compound is non-toxic and safe to use.

In contrast to TBBPA, in vivo data regarding the toxicity of Alpi and ZS are minimal (for review see Waaijers et al. 2013a). The present study is thus the first to demonstrate limited, but insignificant effects of these HFFRs on synaptic (long-term and paired-pulse) plasticity. During LTP, the potentiation of the fEPSP amplitude was only slightly increased in the Alpi mice, while the fEPSP amplitude of ZS mice was close to controls. During sustained LTP, the fEPSP amplitude in both the Alpi and ZS groups was comparable to controls. In addition to these minor and insignificant effects, no effects on expression of synaptic proteins were observed. Despite the use of relatively high doses (211 $\mu \mathrm{mol} / \mathrm{kg}$ bw), ZS and Alpi were undetectable in liver, muscle and brain tissues at PND 17-19. The hydrophilicity of both Alpi and ZS [with $\log \mathrm{K}_{\mathrm{ow}}$ values of -0.4 and $<-1$, respectively (Waaijers et al. 2013a), compared to 4.5 for TBBPA (Birnbaum and Staskal 2004)] may hamper absorption in the gut as well as passage across the blood-brain barrier. Alpi and ZS thus theoretically have a very low bioavailability, which is in line with the few available in vivo studies that report low toxicity (according to REACH regulations of the European Union) based on lethal doses (LD) for feeding, dermal or inhalation exposure (oral $\mathrm{LD}_{50}>2$ $\mathrm{g} / \mathrm{kg}$ for Alpi (rat) and an oral $\mathrm{LD}_{50}$ of $>5 \mathrm{~g} / \mathrm{kg}$ for ZS (rat) (U.S. Environmental Protection Agency (EPA) 2008; William Blythe 2010). Our findings are also consistent with a toxicokinetic study of Alpi (European Chemicals Agency (ECHA) Database 2014) reporting that only a small amount of the Alpi dose was absorbed by the gastrointestinal tract and that the major part was excreted via feces. However, additional data, in particular regarding human exposure levels, are required to determine the human risk associated with the use of these HFFRs. Of importance in this respect, in vitro studies indicate a high neurotoxic potential of ZS (Hendriks et al. 2012b, 2014). It is not unlikely that conditions, which in some way increase the bioavailability of ZS (e.g., $\mathrm{pH}$ ) and/or affect the barriers of the gut and/or brain (e.g., disease), may increase the risk associated with ZS. The low observed toxicity in both in vitro and in vivo experiments suggests that Alpi may be a suitable alternative flame retardant, though additional data are needed to obtain a full toxicological profile for proper risk assessment.

Despite their shortcomings (absence of toxicokinetics, bioavailability, barrier functions and complex cell-cell interactions), in vitro studies are efficient and useful for prioritization, revealing mechanisms of action, and establishing effect concentrations. Although previous in vitro studies revealed HFFR-induced neurotoxicity, the present in vivo/ex vivo study indicates the absence of (developmental) neurotoxicity following one single oral exposure. The experimental setup with a single oral exposure on PND 10 (during the peak of the brain growth spurt) is an efficient and sensitive way to demonstrate the developmental neurotoxic effects of, e.g., flame retardants. This has been demonstrated previously in in vivo and ex vivo studies in which mice exposed on PND 10 to BFRs developed permanent aberrations in spontaneous behavior and habituation capability, protein expression and LTP (Dingemans et al. 2007; Eriksson et al. 2001, 2002; Gee and Moser 2008; Viberg et al. 2003a, b, 2004). Similarly, effect assessment at PND 17-19 (just after the peak of the brain growth spurt) following the exposure on PND 10 has previously been shown to be efficient and sensitive (Dingemans et al. 2007; Viberg and Eriksson 2011). Accordingly, using the same dosing paradigm, possible (developmental) neurotoxic effects of TBBPA, Alpi and ZS can be compared with existing (developmental) neurotoxicity data of BFRs. While we did not observe developmental neurotoxicity following a single oral TBBPA exposure, chronic exposure (which appears more realistic for the human situation) may affect, e.g., auditory neuron function as a consequence of disturbance of thyroid hormones (Lilienthal et al. 2008; Van der Ven et al. 2008). Nonetheless, the present single dose study suggests a low concern for the developing brain following exposure to TBBPA, Alpi or ZS.

In conclusion, despite the in vitro neurotoxic potential of TBBPA and ZS, a single oral exposure to a high dose of TBBPA, Alpi or ZS on PND 10 induced only limited and insignificant effects on synaptic function and plasticity in mice. This is corroborated by the absence of effects on expression levels of synaptic proteins. The overall absence of adverse effects appears due to poor bioavailability of Alpi and ZS and/or rapid elimination of all three flame retardants. However, further risk assessment of HFFRs should also include the physical-chemical properties (e.g., molecular weight, $\log \mathrm{K}_{\mathrm{ow}}$, and water solubility) of 
the compound, production volumes, presence in the environment, persistence, bioaccumulation, ecotoxicity and chronic and/or developmental toxicity in vitro as well as in vivo. Moreover, humans are generally exposed not acutely to a single environmental pollutant, but chronically to (low dose) mixtures of potentially toxic substances. Since interactions with other compounds may result in synergism, additivity or antagonism, mixture studies should also be included for human risk assessments.

Acknowledgments We acknowledge Petra Krystek (Philips Innovation Services, Eindhoven, The Netherlands) for the metal analysis, the Department of Organismal Biology at Uppsala University Sweden for protein expression analysis. This work was supported by a grant from the European Union (ENFIRO; grant agreement FP7ENV-2008-1-226563) and the Faculty of Veterinary Medicine of Utrecht University.

Conflict of interest The authors declare they have no competing financial interests.

\section{References}

Abb M, Stahl B, Lorenz W (2011) Analysis of brominated flame retardants in house dust. Chemosphere 85:1657-1663

Abdallah MA, Harrad S (2011) Tetrabromobisphenol-A, hexabromocyclododecane and its degradation products in UK human milk: relationship to external exposure. Environ Int 37:443-448

Birnbaum LS, Staskal DF (2004) Brominated flame retardants: cause for concern? Environ Health Perspect 112:9-17

Blundon JA, Zakharenko SS (2008) Dissecting the components of long-term potentiation. Neuroscientist 14:598-608

Brady UE (1979) Pharmacokinetic study of tetrabromobisphenol A (BP-4) in rats. Brominated flame retardant industry panel

Cariou R, Antignac JP, Zalko D, Berrebi A, Cravedi JP, Maume D, Marchand P, Monteau F, Riu A, Andre F, Le Bizec B (2008) Exposure assessment of French women and their newborns to tetrabromobisphenol-A: occurrence measurements in maternal adipose tissue, serum, breast milk and cord serum. Chemosphere 73:1036-1041

Colnot T, Kacew S, Dekant W (2014) Mammalian toxicology and human exposures to the flame retardant $2,2^{\prime}, 6,6^{\prime}$-tetrabromo-4, $4^{\prime}$ isopropylidenediphenol (TBBPA): implications for risk assessment. Arch Toxicol 88(3):553-573

Covaci A, Voorspoels S, Abdallah MA, Geens T, Harrad S, Law RJ (2009) Analytical and environmental aspects of the flame retardant tetrabromobisphenol-A and its derivatives. J Chromatogr A 1216:346-363

D'Hulst C, Atack JR, Kooy RF (2009) The complexity of the GABA receptor shapes unique pharmacological profiles. Drug Discov Today 14:866-875

de Wit CA, Herzke D, Vorkamp K (2010) Brominated flame retardants in the Arctic environment-trends and new candidates. Sci Total Environ 408:2885-2918

Dingemans MM, Ramakers GM, Gardoni F, van Kleef RG, Bergman A, Di Luca M, Van den Berg M, Westerink RH, Vijverberg HP (2007) Neonatal exposure to brominated flame retardant BDE-47 reduces long-term potentiation and postsynaptic protein levels in mouse hippocampus. Environ Health Perspect 115:865-870

Dingemans MM, Van den Berg M, Westerink RH (2011) Neurotoxicity of brominated flame retardants: (in)direct effects of parent and hydroxylated polybrominated diphenyl ethers on the (developing) nervous system. Environ Health Perspect 119:900-907

Dobbing J, Sands J (1979) Comparative aspects of the brain growth spurt. Early Hum Dev 3:79-83

Dwyer JB, McQuown SC, Leslie FM (2009) The dynamic effects of nicotine on the developing brain. Pharmacol Ther 122:125-139

Eriksson P, Jakobsson E, Fredriksson A (2001) Brominated flame retardants: a novel class of developmental neurotoxicants in our environment? Environ Health Perspect 109:903-908

Eriksson P, Viberg H, Jakobsson E, Örn U, Fredriksson A (2002) A brominated flame retardant, 2,2',4,4',5-pentabromodiphenyl ether: uptake, retention, and induction of neurobehavioral alterations in mice during a critical phase of neonatal brain development. Toxicol Sci 67:98-103

European Chemicals Agency (ECHA) Database (2014) Exolit OP 930-Toxicological information: experimental supporting basic toxicokinetics 2

Gee JR, Moser VC (2008) Acute postnatal exposure to brominated diphenylether 47 delays neuromotor ontogeny and alters motor activity in mice. Neurotoxicol Teratol 30:79-87

Geyer HJ, Schramm KW, Darnerud PO, Aune M, Feicht EA, Fried KW (2004) Terminal elimination half-lives of the brominated flame retardants TBBPA, HBCD, and lower brominated PBDEs in humans. Organohalogen Compd 66:3867-3872

Giessmann U, Greb U (1994) High resolution ICP-MS- a new concept for elemental mass spectrometry. Fresenius J Anal Chem 350:186-193

Hendriks HS, van Kleef RG, Van den Berg M, Westerink RH (2012a) Multiple novel modes of action involved in the in vitro neurotoxic effects of tetrabromobisphenol-A. Toxicol Sci 128:235-246

Hendriks HS, van Kleef RG, Westerink RH (2012b) Modulation of human $\alpha_{4} \beta_{2}$ nicotinic acetylcholine receptors by brominated and halogen-free flame retardants as a measure for in vitro neurotoxicity. Toxicol Lett 213:266-274

Hendriks HS, Meijer M, Muilwijk M, Van den Berg M, Westerink RH (2014) A comparison of the in vitro cyto- and neurotoxicity of brominated and halogen-free flame retardants: prioritization in search for safe(r) alternatives. Arch Toxicol 88:857-869

Johnson-Restrepo B, Adams DH, Kannan K (2008) Tetrabromobisphenol A (TBBPA) and hexabromocyclododecanes (HBCDs) in tissues of humans, dolphins, and sharks from the United States. Chemosphere 70:1935-1944

Kicinski M, Viaene MK, Den Hond E, Schoeters G, Covaci A, Dirtu AC, Nelen V, Bruckers L, Croes K, Sioen I, Baeyens W, Van Larebeke N, Nawrot TS (2012) Neurobehavioral function and low-level exposure to brominated flame retardants in adolescents: a cross-sectional study. Environ Health 11:86

Knudsen GA, Sanders JM, Sadik AM, Birnbaum LS (2014) Disposition and kinetics of tetrabromobisphenol A in female Wistar Han rats. Toxicol Rep 1:214-223

Krystek P, Ritsema R (2009) An incident study about acute and chronic human exposure to uranium by high-resolution inductively coupled plasma mass spectrometry (HR-ICPMS). Int J Hyg Environ Health 212:76-81

Lilienthal H, Verwer CM, Van der Ven LT, Piersma AH, Vos JG (2008) Exposure to tetrabromobisphenol A (TBBPA) in Wistar rats: neurobehavioral effects in offspring from a one-generation reproduction study. Toxicology 246:45-54

Lisman J, Yasuda R, Raghavachari S (2012) Mechanisms of CaMKII action in long-term potentiation. Nat Rev Neurosci 13:169-182

Nakajima A, Saigusa D, Tetsu N, Yamakuni T, Tomioka Y, Hishinuma T (2009) Neurobehavioral effects of tetrabromobisphenol A, a brominated flame retardant, in mice. Toxicol Lett 189:78-83

Notenboom RG, Ramakers GM, Kamal A, Spruijt BM, de Graan PN (2010) Long-lasting modulation of synaptic plasticity in rat 
hippocampus after early-life complex febrile seizures. Eur J Neurosci 32:749-758

Saegusa Y, Fujimoto H, Woo G, Inoue K, Takahashi M, Mitsumori K, Hirose M, Nishikawa A, Shibutani M (2009) Developmental toxicity of brominated flame retardants, tetrabromobisphenol A and 1,2,5,6,9,10-hexabromocyclododecane, in rat offspring after maternal exposure from mid-gestation through lactation. Reprod Toxicol 28:456-467

Saegusa Y, Fujimoto H, Woo GH, Ohishi T, Wang L, Mitsumori K, Nishikawa A, Shibutani M (2012) Transient aberration of neuronal development in the hippocampal dentate gyrus after developmental exposure to brominated flame retardants in rats. Arch Toxicol 86:1431-1442

Schulz P, Cook E, Johnston D (1994) Changes in paired-pulse facilitation suggest presynaptic involvement in long-term potentiation. J Neurosci 14:5325-5337

Shi ZX, Wu YN, Li JG, Zhao YF, Feng JF (2009) Dietary exposure assessment of Chinese adults and nursing infants to tetrabromobisphenol-A and hexabromocyclododecanes: occurrence measurements in foods and human milk. Environ Sci Technol 43:4314-4319

U.S. Environmental Protection Agency (EPA) (2008) Flame retardants in printed circuit boards 273

Van der Ven LT, Van de Kuil T, Verhoef A, Verwer CM, Lilienthal H, Leonards PE, Schauer UM, Canton RF, Litens S, De Jong FH, Visser TJ, Dekant W, Stern N, Hakansson H, Slob W, Van den Berg M, Vos JG, Piersma AH (2008) Endocrine effects of tetrabromobisphenol-A (TBBPA) in Wistar Rats as Tested in a onegeneration reproduction study and a subacute toxicity study. Toxicology 245:76-89

Viberg H, Eriksson P (2011) Differences in neonatal neurotoxicity of brominated flame retardants, PBDE 99 and TBBPA, in mice. Toxicology 289:59-65

Viberg H, Fredriksson A, Eriksson P (2003a) Neonatal exposure to polybrominated diphenyl ether (PBDE 153) disrupts spontaneous behaviour, impairs learning and memory, and decreases hippocampal cholinergic receptors in adult mice. Toxicol Appl Pharmacol 192:95-106
Viberg H, Fredriksson A, Jakobsson E, Orn U, Eriksson P (2003b) Neurobehavioral derangements in adult mice receiving decabrominated diphenyl ether (PBDE 209) during a defined period of neonatal brain development. Toxicol Sci 76:112-120

Viberg H, Fredriksson A, Eriksson P (2004) Neonatal exposure to the brominated flame-retardant, 2,2',4,4',5-pentabromodiphenyl ether, decreases cholinergic nicotinic receptors in hippocampus and affects spontaneous behaviour in the adult mouse. Environ Toxicol Pharmacol 17:61-65

Viberg H, Mundy W, Eriksson P (2008a) Neonatal exposure to decabrominated diphenyl ether (PBDE 209) results in changes in BDNF, CaMKII and GAP-43, biochemical substrates of neuronal survival, growth, and synaptogenesis. Neurotoxicology 29:152-159

Viberg H, Ponten E, Eriksson P, Gordh T, Fredriksson A (2008b) Neonatal ketamine exposure results in changes in biochemical substrates of neuronal growth and synaptogenesis, and alters adult behavior irreversibly. Toxicology 249:153-159

Waaijers SL, Kong D, Hendriks HS, de Wit CA, Cousins IT, Westerink RHS, Leonards PEG, Kraak MHS, Admiraal W, de Voogt P, Parsons JR (2013a) Persistence, bioaccumulation, and toxicity of halogen-free flame retardants. Rev Environ Contam Toxicol 222:1-71

Waaijers SL, Hartmann J, Soeter AM, Helmus R, Kools SA, de Voogt P, Admiraal W, Parsons JR, Kraak MH (2013b) Toxicity of new generation flame retardants to Daphnia magna. Sci Total Environ 463-464:1042-1048

William Blythe (2010) Material safety data sheet (MSDS)—Flamtard $\mathrm{S}$ (zinc stannate)

Williams AL, DeSesso JM (2010) The potential of selected brominated flame retardants to affect neurological development. J Toxicol Environ Health B Crit Rev 13:411-448

Xing T, Chen L, Tao Y, Wang M, Chen J, Ruan D (2009) Effects of decabrominated diphenyl ether (PBDE 209) exposure at different developmental periods on synaptic plasticity in the dentate gyrus of adult rats in vivo. Toxicol Sci 110:401-410 